\title{
TEACHING UNDERGRADUATE REGIONAL ECONOMICS
}

\section{INTRODUCTION}

At the 38th North American Meetings of the Regional Science Association International (RSAI) held in New Orleans in November 1991, a three-hour session was devoted to the teaching of regional economics. In this session, organized by James Kurre of Pennsylvania State University-Erie, eight individuals described "how" they teach the undergraduate regional economics course at their home institutions. Two panels were convened. In the first, John Blair, Roger Bolton, Jarvin Emerson, and Frank Giarratani described course structure and content. In the latter panel devoted to course projects, participants included Andrew Isserman, James Kurre, William Latham, and Karen Polenske.

All of those participating in these presentations agreed that such an exchange of ideas was very beneficial and would likely be of interest to a larger audience than that attending the RSAI meetings. Given this potential interest, the editors asked the six participants who currently teach undergraduate regional economics within economics (as opposed to planning) departments to prepare short papers describing their courses for publication in the Review. Each author (teacher) was requested to comment upon: (1) the "goals" for his course, (2) the nature of the students in attendance, (3) the text employed as well as any supplementary reading material, (4) course content, and (5) any special projects or assignments. Although reading lists and other class material are not included in what follows, each contributor has agreed to make such information available upon request. 


\section{John P. Blair \\ Wright State University}

Organizing a first course in urban-regional economics is a bit like piecing together a jigsaw puzzle: there is no best starting place nor is there one best path. But at least a jigsaw puzzle has definite boundaries, and when all the pieces are fitted, the task is complete. Urban and regional economics lacks clear boundaries and always seems to include more that should be taught. Consequently, this paper is intended to discuss potential points of emphasis, rather than to describe a "master syllabus."

\section{EXPECTATIONS}

The variety of expectations faced by regional economics teachers contributes to variations in course content. Differences in the title of the first course in spatial economics affects expectations. At some universities, the first course in spatial economics is labeled "urban" economics. Elsewhere, it is termed "regional" economics. In practice, the distinction between these two courses is nearly nonexistent. Regional economics generally emphasizes location theory and input-output models, whereas urban economics tends to emphasize the "new urban economics" and a litany of urban problems (many left over from the early 1970s). However, the theoretical models and policy concerns overlap so pervasively that I prefer to think of the first spatial economics course as an urban-regional course.

Students in their first urban-regional class have an extremely wide range of expectations. I teach at Wright State, a public, practically open-enrollment university where students tend to be interested in career-oriented topics and issues focusing on the Dayton region. I also teach as an adjunct professor at Antioch College, a small, elite liberal arts school where students' interests are oriented toward the political and social aspects of regional development and global urbanregional concerns. In neither case do student expectations accurately reflect traditional course content, however broadly defined.

As part of the introductory lecture, I have found it useful to close the gap between what is planned for the course and what students expect the course to cover. One way to do this is to ask the class to list what they expect to learn in the course. I then examine the topics at random. Some student questions can be answered quickly in one or two sentences; others are beyond the scope of the 
course. Explaining why topics will not be covered provides students with a basis for understanding the logic of the course. The majority of the items listed by students, however, can be incorporated into topics already in the course syllabus. The discussion provides an opportunity to explain how a broad understanding of various regional economic topics can establish a framework for addressing the specific interests expressed by the students.

We should be tolerant of variations in course content because of the variety of expectations and the scope of the material, but we should be intolerant of boredom. An interesting course can compensate for almost any other reasonable vice, and there are several features of urban-regional economics that usually spark student interest.

\section{ATTRACTIONS OF URBAN AND REGIONAL ECONOMICS}

\section{Policy}

Many students complain that their courses lack relevance. When students say, "It may be true in theory, but not in reality," they often mean that the theory is so stilted that it cannot be applied. Policy concerns help relate theory to practice, transforming what could be mere academic exercises into ideas that affect lives.

Today the newspapers regularly report on regional economic issues. The emerging recognition by macroeconomic forecasters of the "swiss cheese" economy highlights the importance of regional variations (a fact regional economists recognized long ago). It is useful to bring to class newspaper clippings that illustrate regional economic issues in various parts of the world. Drawing upon local issues is particularly effective in metropolitan universities because most of the students can form a concrete picture of the examples. They may have thought about policies to deal with noticeable local problems before the class discussion.

In a related vein, regional policies were designed to directly affect people's lives. The bridge between regional policies and the quality of life of residents is very direct. Regional economics really is "economics as if people mattered." The concern with people, which is so strong in regional economics, contrasts with the rigorous theoretical approaches that have filtered into undergraduate programs. 


\section{Theory}

In many field courses, theory is often a restatement of micro or macro theory (Siegfried et al. 1991, 103). The word "worker" might be substituted for "resources," but the models are very similar. In contrast, regional economic theory is distinctive from the main body of economic theory rather than merely derivative. Many students respond with particular enthusiasm to four unique aspects of spatial theory.

First, location theory is grounded in microeconomics, but the traditional micro textbooks do not cover it. There are two ways to discuss location theory. One is through formal models, and the other is through a less rigorous discussion of important locational factors. These two approaches blend well. Concrete location factors are familiar to students, exemplified in local environments, and relevant to the theory.

Second, the concepts of demand in a spatial context provide students with a new perspective on an established topic. The idea that space alone is enough to differentiate products suggests that the monopolistic competitive solution for a firm is likely even when the product would otherwise be considered competitive. In space, the competitive solution becomes almost trivial.

Third, central place theory underlies the development of a system of cities and provides insights regarding how metropolitan regions are organized. Some students are intrigued by the snowflake regularity of the model. Others are confused by the incongruities between the model's predictions and reality as they see it. It is useful to spend ample class time evaluating the central place model. By pointing out its strengths and weaknesses, the instructor can help temper the attitude of students who would otherwise get carried away with the theory. Thus, the majority of students who like to keep a realistic security blanket close at hand can see the advantages of the theory.

A fourth unique theoretical aspect of regional economics is the monocentric model of urban areas as described by Mills and expanded in numerous articles. The monocentric models have become increasingly less relevant in light of the development path of metropolitan regions. The multinucleated model better describes the metropolitan area. Nevertheless, the introduction of space into the model renders the monocentric model unique. It is not a routine application of traditional economic theory. The monocentric model can be used as a platform for describing forces at work within the multinucleated region.

Of course, there are other theories that should be included in an introductory urban-regional course, even though they are plainly derived from traditional economic theories. The export base theory, for instance, is Keynesian economics. 
To further build the analogy, one may compare export-base theory with supplyside approaches to regional economics.

Like most instructors, I find a way to discuss the problem of the commons, the Coase Theorem, the Tiebout Model and "Baumol's disease," and other aspects of traditional economic theory that have important regional applications even though the theory itself is not uniquely regional.

Two curriculum changes are likely to affect the way regional economics theory is taught in the future. First, the concept of spatial demand and spatial market structures is likely to be incorporated into the standard intermediate microeconomic theory textbooks. Second, the distinction between regional and intemational economic theory will evaporate. As barriers to mobility fall, the traditional case in which international theory concerns situations where products are mobile and resources are immobile will become a special case of a more general regional model.

\section{Interdisciplinary Nature}

The development of an interdisciplinary perspective is considered to be a desirable goal of economics field courses and undergraduate education in general because the interdisciplinary approach provides depth to the curriculum. As the National Advisory Committee (1989) noted:

Depth cannot be reached merely by cumulative exposure to more and more . . . subject matter. It requires that students grapple with connections across subject matters. It implies that students develop the capacity to discern patterns, coherence and significance....

Regional economics easily accommodates a multidisciplinary framework. Any time real-world problems are examined, disciplinary boundaries break down, whether it be transportation, poverty, land use, budget deficits, or heart disease. The use of ideas derived from fields outside of economics contributes to the interesting nature of the introductory urban-regional course.

Buchanan and Tullock (1971) likened interdisciplinary studies to "fence plowing." It is harder to plow by the fences, but because the land is virgin, it is more fertile. Some of my most interesting, productive classes have occurred when students explore interdisciplinary areas. Incorporating interdisciplinary perspectives is appreciated when teaching a class of mixed majors. Noneconomics majors tend to feel more comfortable about economics if they see clear links to their home base. An interdisciplinary perspective is nearly essential for some economics majors who believe that economics has nearly all the answers. 


\section{Use of Community Resources}

Student interest in urban and regional economics can be enhanced by using available community resources. Members of neighborhood groups, chamber of commerce representatives, planners, and officials from a variety of other groups are usually willing to discuss how their work relates to urban or regional economics. I have used speakers from the community sparingly in the past because I was concerned with covering the chapters (and because I was embarrassed that the university lacks funds to pay the guest speakers). However, in light of recent student reaction, I intend to use guest speakers more often.

\section{Special Projects}

Special projects offer opportunities to apply regional economic concepts. I use two types of simulations as special projects. One project requires students to work with a cash flow statement for a hypothetical building. Income and expenditures can be placed on a spreadsheet for the life of a particular project. Value can be determined (discounted value of net income) and compared to hypothetical construction costs. By examining the residual to land after expenses have been deleted from income, students can understand how the principle of highest and best use can be applied. Students are encouraged to examine how the value of land will be affected under alternative assumptions regarding cash flow, the degree of financial leverage, and interest rates. Land use decisions can be simulated by hypothetical financial models of different property types.

Another project involves computer simulation, using the program Sim City. The program allows students to zone a city, place roads and other infrastructure, and set tax and expenditure levels. The output includes an eight-page map, land values, and a variety of indicators of citizen welfare and regional development.

Sim City is enjoyable for most of my students because it can be played as a pure game. To insure that it is a learning experience, I require a short paper describing how each student planned to develop his or her city, evaluating the results, and comparing the operation of the simulation with reality.

\section{REFERENCES}

Buchanan, James M., and Gordon Tullock. The Calculus of Consent. Ann Arbor, Mich.: The University of Michigan Press, 1971. 
National Advisory Committee to the Association of American Colleagues. Project on Study-in-Depth, Liberal Education, and the Arts and Sciences Major. Unpublished. 1989

Siegfried, John G., R. L. Bartlett, W. L. Hansen, A. C. Kelly, D. N. McCloskey, and T. H. Tietenberg. "Status and Prospects of the Economics Major." Journal of Economic Education 22, no. 3 (1991): 197-224. 


\section{Roger E. Bolton \\ Williams College}

I have taught regional economics in various places and in various ways, so I will describe something like my "ideal" course, rather than any actual course I have taught.

Every course is shaped by the students and the department, so I need to describe the context that they create. My students are liberal arts college students, and their primary interests in taking a regional economics course are not very "vocational." They are not planning or marketing or geography students, and they are more likely to see international economics or finance as the departmental offering that increases their immediate employment prospects. They are looking for applications of economics that interest them, either because of where they live or where they plan to work.

Very few students are interested in Williams's own region, but they may be very interested in their home regions. Therefore, I need to structure the topics and assignments so they can study a variety of regions, with at least one region researched in depth in a paper. Most of our students live in metropolitan areas that are influenced by a single large city, so my course has a healthy dose of urban economics as well.

My department often has two elective courses in an applied subject: one is accessible to students who have had only a one-semester (read, "rushed") principles course; the other is an advanced elective for majors that requires prior work in intermediate theory (micro, in the case of regional economics) and also requires a research paper. The majority, but not all, of the students in the second course will have had some econometrics, and I find that heterogeneity is the single biggest headache in designing an advanced course. The department requires that a lower-level elective reinforce and expand theory from the principles course and that an advanced elective apply intermediate theory. In what follows, I will often describe a topic that is logical for an advanced course but not for a lower-level one.

Sometimes I have used Hoover and Giarratani (1984) as a text, sometimes no single text at all, but in either case, there are many journal articles and book chapters and many of my own handouts that fill in gaps in the students' theoretical background.

Now to the topics of the course. A good way to start is with the unusual aspects of regional economies and regional economics, referring to a "wide-open" 
economy that cannot on its own change its exchange rate, cannot set its own defense budget, and specializes on the basis of comparative advantage. Sometimes I present fairly formal trade theory.

Edgar Hoover's "three foundation stones" work well as an early organizing principle (they include: immobility of "land," economies of scale, and imperfect mobility of goods and services [Hoover and Giarratani 1984, 4-5]). I hypothesize a newly discovered island continent, with immobile natural resources (rivers, an ocean harbor, and ore deposits), and then proceed to "populate" it in specialized urban areas, including a capital city/services center.

It is also important to show early the incredible variety of regional definitions: official (e.g., states, counties, metropolitan statistical areas, Census Bureau multistate "divisions" and "regions"); physiographic; ones by regional geographers, which are interesting because they do not respect political boundaries; ${ }^{1}$ David Huff's (1973) "spheres of influence;" and Garreau's (1981) "nine nations" of North America.

My next move is perhaps unusual: I teach regional input-output analysis early in the course, starting with a real-world transactions table-usually one of Phil Bourque's (1987) tables for Washington (about 50 industries). The table allows me to mention the three broad sectors of the economy-primary, secondary, tertiary-to review national income accounting and to show forward and backward linkages. The empty cells are some of the most important ones.

Next I demonstrate input-output multipliers, using my own long handout (I have never found any published item that really suits me as text material on inputoutput!), numerical examples, and intuition rather than matrix algebra. Highspeed spreadsheet programs are a boon here; one goal is to show what happens in a 50-sector model in a short period of time. On the other hand, I think students get a better intuitive grasp if they work and interpret a variety of numerical examples for a much smaller economy, and I assign problems based on either a six-sector hypothetical model or a 15 -sector real one in both the open and the closed versions.

Economic base models follow logically, as severely aggregated models, and as the regional analogue of simple Keynesian macro demand models (that reinforces the principles/intermediate macro courses). I emphasize that the multiplier is small in many regions-students will need to remember that later in life to protect the public interest against wildly inflated estimates by boosters and subsidy seekers.

As do many teachers, I spend a lot of time on location theory. I emphasize graphical approaches and also use my own simple computer simulation model. The model essentially simulates different locations on a "Hoover Diagram," but the firm needs two inputs, not just one, and it has a Cobb-Douglas production 
function and nonlinear freight costs. One input must be transported; one is ubiquitous (except at a few locations that have cost differences due to taxes or environmental protection costs). The firm minimizes production costs at any possible location and chooses the location that maximizes profits. The optimal input combination varies with location. It is useful for the student to actually step along the entire profit line, but an alternative is to use a nonlinear programming model that finds and displays the optimal location. ${ }^{2}$

Agglomeration economies are important, especially if one emphasizes, as I do, the role of large cities. The analysis of them permits review and expansion of students' knowledge of production functions and of growth theory, so the topic applies to both micro and macro. I need my own long handout here, for ordinary microeconomics texts do not cover real production functions adequately to prepare students. I also summarize and explain some empirical studies, such as the one by Hulten and Schwab (1984), although I do not always assign any of them.

Migration is a natural topic; a clear majority of Williams students have migrated in their lifetime and/or expect to move soon to a region other than the one where they now live. One should distinguish the "disequilibrium approach" and the "equilibrium approach." Students get a kick out of Blomquist, Berger, and Hoehn's (1988) study-usually at least one student who knows an urban area well will find a result surprising or even silly and is willing to say so. Such a study also provides a good review of the difficulties of regional econometric analysis and an example of the hedonic approach. Even students who have not had econometrics yet get the point.

I will close by discussing two topics that are special to my course. The first is the economic interpretation of a "sense of place," which is a research interest of mine; I ask students to read one of my papers and also to discuss how my ideas affect their views on "'place prosperity' versus 'people prosperity." The topic complements migration well.

The second topic is regional econometric modeling. Often I demonstrate to the class a real-world operational model; I have been able to use a REMI model (from Regional Economic Models, Inc., Amherst, Massachusetts) several times and am grateful to George Treyz for his assistance. That model works best, however, when a large part of the class has a common interest in one region, so it is more useful when teaching at a state or urban university than at Williams (extensive simulations of the REMI Wisconsin model greatly interested students at University of Wisconsin, where I taught a course jointly with Michael Wiseman). Such a demonstration requires a great deal of advance preparation.

Finally, a word about the research paper. Here is where students can explore their home region in depth if they wish. Not every student wishes to do that. A 
student might write instead about interregional variation in some economic phenomenon. In one of the most interesting papers I have received, a student strong in both economics and American history used location theory to analyze the historical shift of the New England whaling industry from Nantucket to New Bedford.

\section{ENDNOTES}

1. I show students Birdsall and Florin's (1992) 18 regions, which are interesting in these respects: the boundaries cross state and national (U.S.-Canadian) lines; very traditional ones are missing-parts of New England are in three different regions; and they have evocative names, such as "The Bypassed East." Finally, territories are overlapping. For example, the region called "California" includes Reno and Las Vegas, as well as the state of California, and parts of the state of California are also in three other regions. Scranton, Pennsylvania, is in three different regions.

2. I have experimented with an interactive BASIC program that writes a model in GAMS, which the GAMS package can then solve; the student need not actually learn GAMS. However, in order to use GAMS and its solvers in assigned problems, one needs student lab space with fast computers, and no one will be surprised to hear that it is not always easy to get the "solver" to reach what is obviously the best location in a highly nonlinear problem!

\section{REFERENCES}

Birdsall, Stephen, and John Florin. Regional Landscapes of the United States and Canada. 4th ed. New York: Wiley, 1992.

Blomquist, Glenn, Mark Berger, and John Hoehn. "New Estimates of Quality of Life in Urban Areas." American Economic Review 78, no. 1 (1988): 89-107.

Bourque, Philip J. The Washington State Input-Output Study for 1982. Seattle:

Graduate School of Business, University of Washington, 1987.

Garreau, Joel. The Nine Nations of North America. Boston: Houghton Mifflin, 1981.

Hoover, Edgar, and Frank Giarratani. An Introduction to Regional Economics. 3rd ed. New York: Knopf, 1984.

Huff, David. "The Delineation of a National System of Planning Regions on the Basis of Urban Spheres of Influence." Regional Studies 7 (1973): 323-9. 
Hulten, Charles, and Robert Schwab. "Regional Productivity Growth in U.S. Manufacturing: 1951-78." American Economic Review 74, no. 1 (1984): 152-62. 


\section{Jarvin Emerson \\ Kansas State University}

As a preamble to my assignment to present the content of a current undergraduate course in regional economics, I would like to make a few observations about how the course has changed in recent years to arrive at its current structure. Certainly, the course has changed to incorporate new ideas and shifts in problem emphasis; however, the most significant influence on the course has been changes in the characteristics of the students taking the course. Three changes stand out: (1) the expected mathematical and computational skills of the students have increased, (2) a smaller percentage of students are from professional schools such as planning and business, and (3) a higher percentage of students are from other countries.

The course structure and illustrative examples have changed to reflect these different student characteristics. The following is a sketch of topics covered.

\section{Regional Problems}

In order to help students understand the focus of a course in regional economics, briefly introduce them to the type of problems addressed by regional economics both currently and historically. These problems can include distressed areas, boom-bust towns, cyclical instability, growth differentials, environment, energy and resource problems, interjurisdictional spill-overs, metropolitan regional problems, nonmetropolitan regional problems, and policy impacts.

\section{Regional Structure}

To provide a basis for understanding regional economic structures and differences in these structures among regional economies, regional input-output models are discussed. A simple model is introduced along with the rudiments of an input-output system. Once the concepts are covered, two types of exercises are explored. The first compares differences in economic structure among various regions by using different input-output models for states, metropolitan regions, and nonmetropolitan regions. This exercise helps to sensitize students to unique regional economic structures. The second exercise involves calculating impacts of external and internal economic events on several different regional economies in order to illustrate how different the magnitude of the impacts may be among dif- 
ferent regional economies. The calculations are made with the use of spreadsheet-type programs and a personal computer. Both generic spreadsheets and custom-designed input-output programs have been used.

\section{Location Theory}

This section of the course attempts to provide reasons for the different regional economic structures. The economics of the firm in a spatial context is covered, with the usual discussion of transportation costs and other spatial cost differentials and their resulting implications for location patterns and regional economic structure. Reference is made to input cost structures within the framework of the input-output model, as well as to a more theoretical microeconomics treatment of the firm in a spatial context. Spatial competition is introduced by using the Stevens game theory adaptation of the Hotelling model, which is followed by presenting spatial equilibrium models with various spatial market configurations and outcomes. This leads into a discussion of central place theory and agglomeration economies.

\section{Demand-type Regional Models}

The simple economic (export) base-type model is introduced and evaluated, which leads into Keynesian-type regional growth models with an emphasis on exports and imports. The input-output framework is revisited. Interregional income theory is linked to the discussion of interregional factor flows. Short-term regional economic performance, instability problems, and long-term growth are examined with demand-driven models. Several extensions of demand-type models, such as the center-periphery models, are explored for their implications for regional growth differentials.

\section{Supply-type Regional Growth Models}

A generalized regional production function is set forth as a framework for examining sources of regional growth and decline. Brief mention is made of some early simple theories such as sector theory and stages-of-growth theory. However, the main emphasis of this section is on neoclassical-type growth models in a regional context, with references to Borts and Stein, Ghali, Olson, etc. Product cycle implications, the regenerative capabilities of a regional economy, cumulative causation, the macroeconomics of unbalanced growth, and long waves are among several related topics that receive attention. 


\section{Regional Policy}

The economic rationales for policy intervention are considered. Externalities, exclusionary problems, and the other usual public goods problems are introduced. Various methods of policy intervention are discussed, including rules, taxes, subsidies, and expenditures.

\section{Lagging Regions}

The demand-type and supply-type models and policy considerations are utilized to explain why some regions grow more slowly than others. Examples from both developed countries and developing countries are used. The successes and failures of policies to stimulate the economies of lagging regions are considered.

\section{Interjurisdictional Spillovers}

This section examines the problems posed by interjurisdictional spillovers, such as environmental problems that originate in one region but affect another, and the lack of correspondence between taxes generated and benefits received. A variety of models are considered, including a Tiebout world. Alternative policy options are examined.

\section{Metropolitan Regional Problems}

While earlier discussions focused on the economic advantages associated with agglomeration, this section deals with some of the problems associated with large metropolitan regions such as congestion, pollution, and public safety. Differences in metropolitan regions, such as industrial structure, level of development, and age, are associated with different problems and solutions. Examples include metropolitan regions in a variety of countries.

\section{Nonmetropolitan Regional Problems}

Because more diversity may exist among nonmetropolitan regions than metropolitan regions, a typology of nonmetropolitan regions is set forth ranging from recreational-based to agricultural-based regional economies. The unique regional problems of each of the regional types are explained, and policies to address them are evaluated. The problems of the rural regions of developing countries are considered. 


\section{Boom-Bust Regions}

A regional problem for some regions has been the boom-bust phenomenon. A variety of different factors have caused massive and often swift changes in the economic fortunes of some regional economies. A change in government policy, the depletion of a resource, a sharp change in relative prices, or a construction project are among events that can change the economic well-being of a regional economy within a short time frame. Both the problems and the potential solutions are considered.

\section{Policy Impacts}

A major problem for regions is the impact of policy on their economic performances. The purpose of this section is to sensitize students to the impact of policy on a regional economy and to offer policy evaluation approaches.

\section{Alternative Futures}

This section contemplates possible future settlement patterns based on several scenarios. What will an information-based society mean for future regional development? Will regions become more specialized? What will increased global competition mean for the regional economies of various countries? 


\section{Frank Giarratani \\ University of Pittsburgh}

The course offerings in regional economics at the University of Pittsburgh serve primarily undergraduate majors. The department requires that all majors take two upper-division courses that have intermediate theory as a prerequisite. The purpose of this requirement is to reinforce each student's understanding of theoretical tools in the context of applied areas. There is a two-course sequence in regional economics that serves this objective: Introduction to Regional Economics (ECON 1300) and Methods of Regional Analysis (ECON 1310). This discussion concerns the methods course. However, the introductory course will be described briefly for perspective.

The first course in the regional sequence, ECON 1300, uses Hoover and Giarratani (1984) as a text. There are no supplementary readings or class projects. The course and the book present regional economics as concerned with the analysis of the spatial distribution of economic activity and with the consequences of economic change in this context. There is dual emphasis on extending economic theory to a spatial dimension and in learning about regional economies, per se. In this respect, the course builds from individual location decisions to macro analysis of regions as systems.

Throughout the course, emphasis also is placed on applications and extensions of traditional topics in principles and intermediate theory. In the treatment of location theory, for example, the importance of assumptions in simplifying problems for analysis is emphasized along with the principle insights drawn from this literature. In this respect, the location problem is presented in full descriptive complexity before it is reduced by assumptions to the classical transfer-cost minimizing context. Subsequent topics are then related to the relaxation of one or more of the restrictive assumptions used in the initial discussion. Similarly, when topics in land use are discussed, the emphasis is jointly on what the models have to say and on the basic principles that they reinforce. We emphasize (1) the classical idea of land rents equalizing rates of return over space and (2) the demand for land as derived from product demand in order to show how changes in product markets work themselves out in a spatial context.

Two years ago, Methods of Regional Analysis was introduced to the undergraduate curriculum. It is designed to give students with an interest in spatial economics an opportunity to use theory in an empirical context. Students taking 
this course typically have had intermediate microeconomic theory as well as the introductory course in regional economics.

The course is structured around a central topic: drawing the distinction between description and explanation. The requirements include a number of applied assignments, and students are expected to use Lotus 1-2-3 in completing this work. Early assignments in the course are based on a data set provided to each student. The data consist of time series of employment at various levels of aggregation by sector for the Pittsburgh region. The format of the course includes workshops that introduce computer and mathematical tools and provide an opportunity to discuss problems raised in lectures or assigned as homework.

The introduction to the course is methodological. We take a logical positivist approach to explanation and build an awareness of the role of theory in explanation (Margeneau 1966; Silberberg 1978; Giarratani 1980). The students are asked to think abstractly about how explanations have been developed in other courses they have taken, to see the common structure in these explanations, and to examine the role of empirical analysis in this process. After the introduction, the structure of the course consists of four parts: (1) descriptive methods, (2) shiftshare techniques, (3) economic-base analysis, and (4) input-output analysis.

The first part-descriptive methods-presents standard material on descriptive statistics (e.g., Kane 1968). Much of this material is not new to the students; as majors in economics, they are required to take elementary statistics. But our emphasis is on using the tools to describe the data well, present findings clearly, and pose questions that "demand" explanation (or, at least, that might pique one's interest in further analysis). Students are asked to read one or two papers that are highly descriptive. These papers have used standard techniques for description over time, description across space, or both.

The first workshop session has a dual purpose. First, instruction is given in Lotus 1-2-3, which is the basic software used in the course. Second, in the sessions and as homework, students are asked to describe the behavior of employment for a particular aggregate industrial or service sector and its component subsectors using tables and graphs as well as a paragraph or two of text. In class, students are asked to go to the chalkboard, discuss their approach to the assignment, and present their findings. In these presentations, the class as a whole is asked to offer possible explanations of the facts that are exposed, and this opportunity is taken to emphasize the use of theory in building explanation, however casual the explanation might be.

Shift-share techniques are introduced because they are widely applied and useful (Doeringer, Terkla, and Topakian 1987; Bendavid 1991). Students are confronted with the fact that shift-share seems to enhance understanding by offering an explanation of sorts, but they are immediately challenged to reconcile this con- 
cept of explanation with that based on the use of economic theory. This approach has successfully raised student awareness. The problem is presented to students in a direct and simple way: first, we observe the fact that a certain amount of employment change occurred in a study region. Second, before shift-share is introduced, students are asked to offer possible explanations, and their responses are translated by the teacher into arguments based on explicit market models. Third, shift-share is introduced and applied, and students are challenged to evaluate the insight offered by this technique as a descriptive device and as a basis for explanation. The workshop concerning shift-share analysis involves a straightforward application of the technique.

Economic-base analysis offers an opportunity to show students the basic structure of economic analysis: identity, behavior, and reduced form. Readings for the export-base model are drawn from several sources, including Pleeter (1980), Hoover and Giarratani (1984), and Shaffer (1989). We then emphasize the use of theory to enhance understanding of the limitations of the model. In this respect, we use Wilbur Thompson's discussion of the intra-area "wage rollout" concept to link labor market performance and the explanation offered by export-base models. At this point in the course, we explicitly introduce the "estimation problem." Accordingly, the workshop and problem set concern alternative estimates of exportrelated employment when the location quotient bifurcation method is applied at different levels of sectoral aggregation.

Before proceeding to input-output (I-O) analysis, two full weeks are devoted to linear algebra. Again, problem sets are used to reinforce learning. This introduction and subsequent readings on the I-O model draw upon Miller and Blair (1985). For a few students, the lectures on matrix algebra are a review, but for most, it is their first exposure to matrix methods. Of course, one cannot do justice to this material in four lectures. However, the objective is for students to learn basic tools; we do not expect to produce experts in I-O analysis. Ultimately, we can use I-O to emphasize once again the importance of theory in understanding the value and limitations of our explanations.

The development and application of input-output models extend the discussion in a number of ways. First, they show the power of simple mathematics in an empirical context. Second, they offer an opportunity to reinforce the important role played by the assumptions of a model in determining its explanatory power. Third, the complexity of the estimation problem is developed. Fourth, the breadth of applications that are available for discussion demonstrates the value of economic analysis in the marketplace.

As implied, problem sets are assigned at each juncture of the course and for each new set of tools. Students often are required to present their work in class and stand the test of peer criticism. The problem sets are the basis for one-half of 
the course grade. One midterm exam and one exam at the end of the term account for the remaining course credit. The exams are analytical and evaluative in nature.

In conclusion, we should note that the goal of this course is simple: students are provided an opportunity to explore the meaning of explanation and the role of theory and description in that process. Sometime during their undergraduate experience, students should be confronted with the questions asked in this course; indeed, they may well be confronted with such questions in many courses. But, for one whose research interests are drawn to regional economics, it is a real pleasure to see the awareness of students grow in this context.

\section{REFERENCES}

Bendavid, Avrom. Regional Economic Analysis for Practitioners. 4th ed. New York : Praeger, 1991.

Doeringer, Peter B., David G. Terkla, and Gregory C. Topakian. Invisible Factors in Local Economic Development. New York: Oxford University Press, 1987. Giarratani, Frank. "The Scientific Bașis for Explanation in Regional Analysis." Papers, Regional Science Association 45 (1980): 185-196.

Hoover, Edgar M., and Frank Giarratani. An Introduction to Regional Economics. New York: Alfred A. Knopf, Inc., 1984.

Kane, Edward J. Economic Statistics and Econometrics. New York: Harper and Row, 1968.

Margeneau, Henry. "What is a Theory?" In The Structure of Economic Science, edited by Sherman Roy Knapp. Englewood Cliffs, N.J.: Prentice-Hall, 1966.

Miller, Ronald E., and Peter D. Blair. Input-Output Analysis, Foundations and Extensions. Englewood Cliffs, N.J.: Prentice-Hall, 1985.

Pleeter, Saul. "Methodologies of Economic Impact Analysis." In Economic Impact Analysis, edited by Saul Pleeter. Boston, Mass.: Martinus Nijhoff Publishing, 1980.

Silberberg, Eugene. "Comparative Statics and the Paradigm of Economics." Chap. 1 in The Structure of Economics. New York: McGraw-Hill Publishing Company, 1978.

Shaffer, Ron. "Economic Base and Input-Output." Chap. 11 in Community Economics. Ames, Iowa: Iowa State University Press, 1989. 


\section{James A. Kurre \\ Pennsylvania State University at Erie}

\section{INTRODUCTION}

As a student, I learned the tools of economic analysis best by actually using them. As a result, I now require students in my undergraduate regional economics course to apply the tools and techniques that we discuss in class to real-world data. Specifically, each student is assigned a metropolitan statistical area (MSA) at the beginning of the semester and proceeds to gather data and perform analyses throughout the semester. Students are required to bring the results to class on specific dates, when we do on-the-spot cross-sectional comparisons and discussion. By the end of the semester, each student has created his or her own economic description of a metro area and, more importantly, has had the opportunity to learn the tools of regional analysis through an ongoing examination of a single metro area. This paper presents my experience with that project, including the pros and cons of adopting the project approach.

\section{GOALS OF THE PROJECT}

My regional economics course is taken by junior and senior undergraduates, mostly business students who are not economics majors, during a 15-week semester. All have had basic micro- and macroeconomics classes, as well as a couple of semesters of statistics and usually at least one computer science course. There are typically from 45 to 50 students in my class on the first day, and I have no teaching or grading assistance.

While I want these students to be exposed to the core material of regional economics, I realize that most will not become regional economists. Therefore, I also want to pursue the more basic goal of having them see how economic theory-even simple supply and demand analysis-can help them understand complicated patterns that they will encounter in the world. As a result, I try to present a sound theoretical base for all the material we cover.

At the same time, I want this class to have a decidedly "applied" flavor, so that students see that theory has a purpose other than just to fill the idle hours of ivory-tower academics. To that end, I require that students apply what we are learning throughout the semester. In the past, I have tried problem sets and exer- 
cises using real-world data to fill this requirement, but I have found that an ongoing, unified project fulfills this need the best. The project described in this paper is the result, and it evolved over several years of experimentation.

My specific goals for the project, which I share explicitly with students early in the course, include:

1) Familiarize students with the sources and types of economic data that are available for regional and metropolitan economies, and make them aware that even simple data are sometimes not available.

2) Help students understand the tools and concepts of regional economics through hands-on use.

3) Teach students about the thought processes involved in examining data-looking for similarities and differences, spotting spurious data, etc.

4) Provide students with the experience of carrying out an extended project in which both form and content are important and that requires them to meet a series of deadlines. Have them learn how to pull together diverse pieces of information and write convincingly about them.

5) Give students considerable experience with both word-processing and spreadsheet software.

I have found that sharing these goals with students helps them to understand the education process and to become partners in it, rather than having education "done to them." It also helps to avoid the "why do we have to do this?" rebellion that can set in when the project gets tough.

\section{MECHANICS OF THE PROJECT}

\section{Basics}

First and foremost, the project is designed to supplement the material covered in the course. Ideally, students are introduced to a concept, see examples in class and in their readings, and then immediately apply the concept to realworld data. In order to have students do this in a timely fashion, I require the project to be done in segments corresponding with the parts of the course. Along the way, I do all parts of the project for our local area, the Erie, Pennsylvania, MSA. Most students are familiar with the local economy so my presentation not 
only helps them understand the concept, but it also provides a model for their own work and a standard against which to judge their results for reasonableness.

On the due date for each part, I give a quick overview of the Erie results again to refresh their memories and then call on a number of randomly selected students to share their findings. Since in-class participation counts as a portion of their course grade, students are usually prepared for these sessions. I always ask if anyone has found unusual results, and we also examine results from the largest and smallest MSAs, the most specialized and diversified, etc. In the class discussion, we look for patterns, similarities, differences, and so on.

I do not require that the project portions be handed in throughout the semester, although that could be easily done. Although this requirement would in fact be a good way to give students feedback on their work as the semester progresses, it would add to the instructor's load. I do, however, write up my own version of the project completely and pass it around the class as an example of what a good project might look like. ${ }^{1}$

At some point, students will start showing up at your office to complain that some of the data they need are not available. I have found this situation to be especially true for employment data from the BLS790 program, since different states and areas have different data collection procedures. You can short-circuit this problem by warning students that some of the required data might not be available for their MSA ("welcome to the real world!") and that they need to deal with this problem if they run into it. I tell my students that they should not come to me with just a problem; they should bring a suggested solution as well. This solution may involve switching to a different MSA or estimating the missing data in some reasonable way. Resolving real-world data problems is one of the key skills that this project tries to teach. I have found that a brief discussion in class of problems encountered by students and of different methods used to resolve them can be an eye-opener after the first assignment, leading to creativity in later portions of the project.

\section{Assignment of MSAs}

At the beginning of the semester, I pass out a long list of MSAs and ask each student to identify his or her top four choices. This list includes the largest and geographically nearest MSAs, as well as several that I expect to have "interesting" characteristics, such as rapid growth or decline or extreme specialization (Washington, Las Vegas, Flint, college towns, state capitals). I encourage students to choose an MSA about which they might wish to learn, perhaps as a possible location for a career after graduation, or to choose an MSA with an unusual economic structure. I also allow them to choose an MSA that is not on the list, if 
they prefer. In assigning MSAs, I try to ensure that the final pool includes a variety of regions and MSA types to give interesting cross-sectional results in our in-class discussions.

One note of caution here: be careful to distinguish among MSA, PMSA, and CMSA definitions in the assignments and to discuss the issue of New England County Metro Areas (NECMAs) versus MSAs. Presumably, defining these terms can be covered in the first part of the course and made explicit by requiring students to determine the exact definition of their area as the first part of the project. This step becomes important when data are available on one basis and not another, or if a student unknowingly mixes the concepts for his or her area.

\section{Computer Matters}

It would be possible to do this project without the aid of a computer, but I choose instead to require students to use a word processor and a spreadsheet. Most students are already familiar with such software packages, but more than a few are not. Rather than use class time to teach these packages, I pass out minimanuals that walk a student through the use of each package on his or her own. ${ }^{2}$ These manuals start from the simplest level possible-where the microcomputers are on campus, what kind of diskette to buy at the bookstore, how to access the software packages, etc. I also point out that our computer center offers free classes in each type of software and give the scheduled times.

In a sense, I am making familiarity with these software packages a prerequisite, or rather a corequisite, for my class. I warn students about this requirement on the first day of class to avoid surprising them with unexpected work later, and most seem to welcome the opportunity to learn a skill that they can later list on their resumé. Most students also seem to feel that they should have learned those skills by this point in their college careers anyway.

\section{Form as Well as Substance}

In trying to prepare students for the world beyond the ivy-covered groves, I tell students to focus on matters of substance, but I stress that form is important as well. How a presentation looks may have an effect on its reception. Likewise, small mistakes and grammatical errors may lead those reading a report to question the credibility of larger matters. ("If he can't even use his native tongue correctly, how can I trust him to have mastered shift-share analysis?")

The importance of "form" has several implications for the project. It means that the final version of the project must be aesthetically pleasing, complete with a title page, table of contents, and complete references to all source documents. Stu- 
dents also learn about formatting a major paper-making sure that all the pages get numbered sequentially, deciding how and if to use underlining and boldface, and knowing how to handle awkward page breaks.

"Form" also involves the more important idea that students must consider the best way in which to present information: how to organize tables of data, when to use graphs, and which information should be on the same page of the report. It entails the requirement that students not only understand the material, but be able to explain it in nontechnical terms to others. The short summary paragraphs have to be concise but inclusive, as well as technically correct. I emphasize that these write-ups must be understandable to the intelligent layman who has not had a class in regional economics. This requirement forces students to interpret and, hopefully, to understand better the tools they are using.

In my experience, students seriously underestimate the amount of time required for this aspect of the project, especially if they have never had to do a major assignment of this length before. In focusing on the substance of the paper, they will ignore the "form" part until the last minute, thinking that it is trivial. I recommend that you warn students about this problem in such a way that they take it seriously. After the last word of analysis and description is written, it often takes my students another two days until the final version of the paper comes off the printer.

\section{Timing}

As previously mentioned, during the semester I require only oral presentation of the individual parts of the project, with the final written version due near the end of the course. I usually allow one week for students to complete each of the individual parts. The deadline for the final project is usually a week and a half before the last class, which helps to avoid the peak-load problem that students often face during the last week of the semester.

Every time I have assigned this project, I have had selected students ask for an extension of the due date. I have found that even the best students may be surprised by the amount of work involved in compiling the final report. In dealing with this situation, I have sometimes allowed a one-time extension of the deadline for the whole class. If I set the initial deadline early enough, I can be magnanimous without running into exam week, and the general extension typically prevents most students from asking for special consideration.

Beyond that, I tell the class that papers may be turned in after the due date at a penalty of five percentage points per day off the top of the grade. This stipulation allows students to make their own choices about the marginal cost and benefit of one more day's work on the paper. While a few students have made bad 
decisions here, I have found that a number of the papers-and the net grades-were better than they would otherwise have been. Students appreciate the option of having some control over their deadlines, and some learn a valuable lesson about applied economics, too.

\section{THE PROJECT ASSIGNMENTS}

Space limitations prevent a discussion here of the individual project assignments. It seems that everyone I have talked to about the regional economics class has a somewhat different idea about what should be covered. With this in mind, I will list only the specific assignments that I have used in my own class, more to give an example than to suggest an ideal to be emulated. In fact, I myself do not expect to use exactly this set of projects next time around. ${ }^{3}$

Since the project is intended to complement the course material, each part of the project corresponds to a topic on my syllabus. Not all topics covered in my class have corresponding project assignments at this point, however. In spring 1991, the project consisted of seven parts:

1. Basic data (demographic and economic).

2. Location quotients and specialization measures.

3. Quality of life and cost of living.

4. Business climate ratings.

5. Shift-share analysis.

6. Export-base analysis.

7. Regional input-output multipliers.

I require students to identify the official definition of their MSAs and then to gather demographic and economic data about them. The economic data includes both employment and income numbers for a specified industrial breakdown for two time periods, which allows calculation of rates of change and comparison through time. ${ }^{4}$

There are a number of changes that could be considered in the content of the project. Three that immediately come to mind are 1) time-series analysis, including perhaps analysis of local cyclical timing and amplitude; 2 ) use of occupational and industrial data; and 3) a concerted policy focus. 


\section{GRADING}

In my course, the project accounts for 22.5 percent of a student's course grade, which is equivalent to each of the three major exams (the other 10 percent is assigned to participation and attendance). The project had a significantly smaller weight in the first year I used it, but students almost unanimously suggested that it play a larger role.

The projects frequently run from 25 to 40 pages in length, which means that a class of 50 students results in a total of from 1,250 to 2,000 pages to read at grading time. Consideration of this cost made me think twice before adopting the project. Grading the project need not be as burdensome as it first seems, however. Much of the project will consist of data arranged in tables or graphs, which can be gone through quickly. Moreover, there are two key techniques that have helped me cut grading time immensely.

First, it is necessary to determine if all parts and subparts of the assigned work have been done. To this end, I have found it useful to create a grading format sheet. This sheet lists all the parts of the project that have been assigned, with corresponding point values for each. Since most students do most parts in an acceptable manner, I simply check off each item as I grade. If a student has omitted a part or done a substandard job, I record negative points on the line for that item; if the student has gone beyond the requirements, I assign extra points. After going through the whole project, I calculate the grade by summing the positive and negative numbers and adding/subtracting the result from the total possible for the project.

It is a good idea to give students a copy of this sheet early in the semester, if possible, to provide them with a checklist for compiling the project and to help them make decisions about allocating their limited time. The completed grading sheet is also very useful in postsemester discussions of grades, when a student shows up at your door puzzled about how he got such a low grade on a project into which he put so much time, and from which he learned so much.

A second key to grading the project relates to the fact that much of the finished project takes the form of tables of data. To the extent that these numbers are calculated by students, grading involves checking their mathematics. A simple way to avoid this problem is to require that students present a complete, detailed example-with numbers plugged in-of their calculations for one data point in each appropriate section. When numbers do not add up in the tables, you can quickly determine whether the student has misunderstood the technique or just made a math error. Also, the more detail you require in the example, the more likely it is that the students will come to understand what they are doing and to avoid the error in the first place. 
As I grade, I also take account of the format of the paper. The grading sheet has points explicitly assigned for overall form/presentation, but when I find something in the form that I particularly like or that particularly annoys me, I add or subtract a point or two in the margin of the grade sheet. In cases where the student has consistently neglected this aspect of the paper or has done an especially praiseworthy job, these points will play a role in the final grade.

I also assign extra points for work done above and beyond the minimum requirements, such as analysis for more than the required number of years. I typically assign relatively small amounts of extra credit, however, so that it is not possible for a student to get a good grade through a "specialization strategy" of doing extra work on a few parts of the project and completely omitting another part.

Overall, I have found the grades on the project to be somewhat higher than the grades from exams (a mean of 80 percent for the project versus 76 percent for the exams in the most recent semester). The range of grades is similar for the project (from 49 percent to 102 percent) and the exams (from 48 percent to 97 percent). I tell students that it is possible for them to virtually assure themselves a high grade on the project by putting in the time required and by asking questions when they run into problems. While the project grades tend to parallel the exam grades across students, a few use the project as an opportunity to pull up their exam grades by a significant amount. The project is also designed to enhance their understanding of the material, so serious attention to the project should raise exam grades as well.

\section{STUDENT FEEDBACK}

Each year that I have used the project, I have heard gripes and complaints about the amount of work involved, typically during the last week before the due date. (On the other hand, I tend to hear gripes about too much work in my other classes, as well. I generally take that as a sign that I am giving them good value for their tuition dollar.) To see whether students viewed the project as an inefficient learning tool with a work load not justified by the learning that resulted, I distributed an anonymous questionnaire to my students at the end of the spring 1991 semester.

Specifically, I asked them to give each portion of the project a rating from 1 (terrible) to 7 (excellent) in terms of its usefulness in helping them learn about the concept or topic. I also asked if each portion should be kept or eliminated in future years and whether or not the whole project should be thrown out. There 
were also some open-ended questions and room for general comments. There were 41 usable responses.

Overall, students gave the project a score of 5.89 out of 7 . Surprisingly, every single student said that the project should continue to be a part of the class, despite the amount of work involved, and despite the fact that some students knew that the project pulled their course grades down. In fact, the lowest grade assigned for the project overall was a four within a scale of 1 to 7 . This reaction was much more positive than I had expected. Given the different abilities of students, their variety of learning styles, and the diversity of their computer expertise, I had expected a wide range of opinions, including some students who absolutely detested the project.

Concerning the individual portions of the project, the location quotient and basic economic data sections rated most highly, while the business climate section was at the bottom of the list by a significant margin. Nearly 40 percent of the students suggested that the business climate ratings portion be dropped from the project. Given that the goal of that portion of the project has been partially met by the quality of life project, and that other potential projects can be substituted for it, I expect to drop this portion of the project in the next iteration.

\section{CONCLUSIONS}

Since we are considering a project for an economics class, it seems logical that conclusions about the project should take the form of a cost-benefit analysis. The benefits to the students parallel the goals listed earlier in this paper. They include familiarity with data sources and definitions; a better understanding of regional economic tools and of data analysis in general; the experience of having completed a major, integrated project; and improved (or new) word-processing and spreadsheet skills. The costs to them include the fact that they wind up spending a lot of valuable time in the computer room and the library, finding and analyzing data, and writing about their conclusions.

The costs to the instructor include a lot of work before the course begins to ensure that the correct data sources are available and that students will have access to computer hardware and software. As the semester progresses, I find students visiting my office more often with questions and problems than they do in other courses. The last week before the project due date can get pretty intense, too. The grading time is also significant; despite the shortcuts mentioned above, it still takes anywhere from 20 to 50 minutes to grade each project, with the bad ones taking much longer than the good ones. 
Perhaps the most significant cost of the project is the opportunity cost in terms of lost class time. I find that students tend to get excited by the class discussion of these topics, and the time goes by faster than anticipated, with the corresponding result being that I cover fewer topics than I had expected. This situation ties in directly to the "breadth versus depth" debate over teaching styles. Is it acceptable to trade breadth of coverage for the opportunity to really delve into a smaller range of topics? The usefulness of a project like the one described here depends crucially on your answer to that question.

On a personal level, I find myself questioning the advisability of the project every year as I slog through the huge pile of project folders. While I am always pleasantly surprised by students' creativity, I am also keenly aware of the hours that I could be devoting to research or to grading the pile of exams from my introductory class.

Despite the fact that some of the worst papers have me tearing my hair out, in the end, I continue to be persuaded by positive student response to the project. The anonymous teaching evaluations I get from each class consistently reveal how much students learned from the project, even though they hated it the night before the due date, and these responses encourage me to continue to use the project. Although I hear lots of horror stories about the long hours and sleepless nights my students endure to complete the project, my regional economics class is oversubscribed every spring. My teaching evaluations have certainly not suffered, either.

The in-class discussions resulting from the project invariably spark interest in techniques that seemed dry and technical when I presented them in strict lecture format. Moreover, some of the perpetually silent denizens of the back row begin to speak up during the intermetropolitan comparisons. A number of students have even dropped by in subsequent semesters to borrow a data source they learned about in "regional" or to tell me how the information they learned in that class has been useful.

Clearly, many of the benefits that I have seen from the project would be very hard to quantify, while the costs seem plain enough. My own assessment is that the benefits to my students are well worth the costs, even though the project is still far from ideal. I expect to continue to use the project and, hopefully, to improve it over the years to come.

\section{ENDNOTES}

1. In past years, I have put my version of the project on closed reserve in the library for student perusal. I discontinued this practice when I found that students 
were just using my format and, sometimes, even my words(!) with slight changes for their projects, rather than making their own decisions about how to present the data and describe them. Passing my version of the project around the class or showing it on the overhead gives them a general idea of how to do the project, but still forces them to decide on the particulars.

2. Such manuals are often composed by staff members of a college's computer center. I personally have found it useful to compose a very brief minimanual for Lotus 1-2-3 that deals with the specific commands that students are most likely to need for the project. A copy of this minimanual is available on request from the author at Pennsylvania State University at Erie, School of Business, Station Road, Erie, PA 16563-1400.

3. This article is based on a paper presented at the 1991 New Orleans RSAI meetings. That paper included details of each section of the project, including data sources and problems, and a more extensive section on student feedback. A copy of the paper, along with the actual project handouts, can be obtained on request to the author.

4. I typically move the "most recent year" forward in time by one year each time I teach the class primarily because I use Bureau of Economic Analysis's Local Area Personal Income data, which are published annually (with a two-year lag), and I like to use the most recent data available. Changing the years used as endpoints also has an important side benefit, though. Students tend to keep a copy of their project, and using the same years for the project each time could result in projects being handed down from one year's students to the next. I have, in fact, seen snatches of a previous year's project show up (somewhat out of context, as it turned out) in a later year's report. Preventing plagiarism is also a good reason for changing the requirements of the project a little from year to year. 


\section{William R. Latham III \\ University of Delaware}

Over the past 17 years, Kenneth A. Lewis, who is also in the economics department at the University of Delaware, and I have jointly continued to develop and refine a course that has held our interest, as well as that of our students, as few courses have done. The title of our course is Regional Econometric Modeling. The course's objective is for every student to master the use of econometric analysis to gain a better understanding of a particular regional economy. Our ultimate measure of success is the quality of a course project report, which every student must complete. Each report must derive a meaningful hypothesis about a particular region from regional economic theory and then rigorously test the hypothesis within a simultaneous equation econometric model of the region.

In the past, we have allowed students to focus on a variety of regional economies. For a number of years, models of other states, other countries (often foreign students' home countries), and Puerto Rico (because I had developed a model there) were used. In recent years, we have required that all of the students contribute to an existing model of the same region: the state of Delaware. We have found that the gains from teaching only one model structure for the empirical work and from students' being able to work together, share data, etc., more than outweigh the loss of freedom of choice and diversity when students choose their own regions. In addition, examples of many regional concepts from the familiar local Delaware economy are readily available and easily communicated. Finally, we have found that, after having experience with the Delaware model, students with very strong interests in another region can and do pursue those interests effectively through a follow-on independent study course.

Enrollment in the course is limited to 16 or fewer advanced undergraduates and first-year graduate students. The undergraduate students are senior economics majors, most of whom are bachelor of science degree candidates with fair to good mathematical skills. Some are enrolled in the liberal arts college, but most are business college students (we offer economics degrees in both colleges). They have all taken intermediate microeconomic theory, two courses in introductory statistics, and at least one course in econometrics; some have had two econometrics courses, and some have had a forecasting methods course; some have had either an urban economics or a regional economics course, although the latter has not been offered in recent years. 
The course is only offered during a five-week term, which lasts from the first week in January through the first week in February. We advise students not to take another course and not to work during this period so that they can devote their full attention to the course. Consequently, we are very successful in getting extraordinarily high levels of student input. We tell students on the first day of class that by the end of the course, they will be eligible to receive the fanciful designation, "Certified Regional Modeler." In fact, by the end of the course, they are highly competent as regional modelers. Over the years, many have obtained employment based explicitly on their competence in this area.

We do not require a published textbook for the course; we rely instead on a prepackaged set of copies of articles and materials that we have generated and refined over the past 16 years as well as on a variety of books and articles reserved for students in the course. We formerly used Glickman's book (1977) and still retain it as a reference. (We tried to keep a chapter from Glickman in our reproduced materials but could not obtain a copyright authorization.) The major articles we use for the theory of regional models include two on different versions of the Delaware model (Butkiewicz and Latham 1991; Latham et al. 1979) and Roger Bolton's (1985) survey of econometric models. The last includes a very large number of references that students use effectively to find theoretical and practical guides for their own research in the course. The prepackaged materials also include two methodological works on econometric modeling in general (Adams and Rowe 1974; Henson and McCracken 1983).

The computer package that we use is MicroTSP, Version 7.0, to which all students have previously been introduced in their first econometrics course. We spend several hours during the first few days and periodically throughout the rest of the course in upgrading the students' skills with MicroTSP and word processing. They are taught how to use MicroTSP to solve a simultaneous equation model, make forecasts with the model, perform simulation experiments, and evaluate the results. Some new word processing skills are necessary because we require that assignments and especially the final project report meet high professional standards both in content and appearance. Students learn how to export tables, regression output, graphs, and equations from MicroTSP and to import them into a word processing document. We have site licenses for MicroTSP and the word processing package, so both are available through our campus network on many personal computers in many locations. The students like the availability of the package through the network because it permits them to work late into the night from any campus location that is open, such as the main library.

In the first part of the course, students are introduced to basic regional concepts and techniques such as export-base analysis, regional and interregional income determination, regional input-output analysis, and shift-share analysis. 
They are also introduced to the idea of expressing regional economic views of the world, as well as concepts from other economics courses, in a set of equations that describe a regional economy. They are reminded especially of the relevance of macroeconomic income determination models and of the microeconomics of production, costs, and consumer demand theory.

On the first day, they are told how to use the computer network to obtain their own copies of the equations and data for a very small (14-equation) model of a hypothetical regional economy. They then use their copies of this model for a series of seven homework exercises that build competence in using simultaneous equation models. They learn modeling procedures such as (1) the production and interpretation of static and dynamic backcasts; (2) the use of impact multiplier analysis; (3) the requirements for real forecasts and ways of estimating and obtaining exogenous data for forecasts; (4) the production of policy simulations through changes in exogenous data, parameters, or alternative equations; and (5) requirements for adding newly estimated equations to a model. The first exercises require hand computation of values, which can then be checked using the computer. This procedure ensures that they understand what the computer is doing; we try to avoid a "black box" approach to modeling.

The last exercise, which requires adding new equations, is particularly instructive because it requires students to understand the significance of a consistent and complete regional accounting framework. This exercise is usually brought home effectively because it requires the disaggregation of a single large industrial sector's equations (for the hourly wage rate, quarterly man-hours, employment, average weekly hours, and quarterly wage bill) into identities and stochastic equations for smaller industries that preserve the accounting structure of the model.

An examination of regional theory and modeling procedures is given at this point in the course. The test is intended to ensure that each student has read and comprehended the assigned materials and has learned from any errors made on the homework exercises.

After the small model has been mastered, each student copies for his or her own use the data files and equations of a larger model (more than 100 equations) of the Delaware economy. Recently, it has been the model described in the Butkiewicz and Latham paper (1991). A series of procedures are then executed so that each student is convinced that the model, as received, can be solved and will produce dynamic backcasts and forecasts. At this point, students are ready to begin work on their course projects.

Each student must select a significant economic hypothesis derived from sound regional economic theory to test. For example, a hypothesis might be "the finance, insurance, and real estate sector should be disaggregated because some components are local industries while others are export-based industries." A for- 
mal proposal must be submitted that describes the hypothesis, the theory from which it is derived, the reason for its significance, and the anticipated outcome. The student must then search the relevant literature for other papers that have dealt with the same or a related problem, looking for guidance in specifying the nature of the disaggregation and for the specification of individual equations. Data are then assembled to permit estimation of the structure of from three to twelve separate stochastic equations.

Once acceptable regression results are obtained (and because of time pressure, really good estimated equations often cannot be obtained), the estimated equations and any required identities are added to the model, and any equations no longer needed are removed. Then backcasts, forecasts, and policy simulations are performed with the new model, and comparisons with the results from the old model are made. Finally, the final paper is prepared with voluminous appendix materials to completely document what has been done. Writing of the final paper is made easier because submission of each of a number of reports is required while the work is proceeding. For example, the original paper proposal becomes, in edited form, the paper's introduction. Reports, which must be submitted on the availability of data and on estimation results for single equations, also become separate sections of the final paper.

The deadline for the submission of the paper is made very firm. Students are told to regard the project as a private consulting job for which they will not be paid if the report is not submitted on time. Our experience has been very gratifying: when students are given sufficient motivation and support, they are capable of responding to challenges and performing at levels beyond which we often assume they are capable. They can become "Certified Regional Modelers" in five weeks.

\section{REFERENCES}

Adams, F. Gerard, and David M. Rowe. Forecasts and Simulations from the Wharton Econometric Model. Morristown, N.J.: General Learning Press, 1974.

Bolton, Roger. "Regional Econometric Models." Journal of Regional Science 25 (1985): 495-520.

Butkiewicz, James L., and William R. Latham. "Banking Development as an Economic Development Policy Tool." Southern Economic Journal 57 (1991): 961-974.

Glickman, Norman. Econometric Analysis of Regional Systems. New York: Academic Press, 1977. 
Henson, Harold, and M. C. McCracken. "Constant Term Adjustments in Large Econometric Models." Unpublished paper from Informetrica, Ltd., Ottawa, Canada, 1983.

Latham, William R., Kenneth A. Lewis, and John H. Landon. "Regional Econometric Models: Specification and Simulation of a Quarterly Alternative for Small Regions." Journal of Regional Science 19 (1979): 1-13. 